\title{
Chronic food-restriction alters the expression of somatostatin and growth hormone-releasing hormone in the ovariectomised ewe
}

\author{
B A Henry, A Rao, A J Tilbrook ${ }^{1}$ and I J Clarke \\ Prince Henry's Institute of Medical Research, PO Box 5152, Clayton, Victoria, Australia, 3168 \\ ${ }^{1}$ Department of Physiology, Monash University, Clayton, Victoria, Australia \\ (Requests for offprints should be addressed to I J Clarke)
}

\begin{abstract}
Changes in the secretion of $\mathrm{GH}$ induced by long-term alterations in nutritional status are thought to result from alterations in somatostatin (SRIF) and growth hormonereleasing hormone $(\mathrm{GHRH})$ at the level of the hypothalamus. To date however, the effect of nutrition on the gene expression of SRIF and GHRH in a species where $\mathrm{GH}$ secretion is increased by food restriction, as is the case for the sheep and human, remains unknown. We determined the effect of under-nutrition on the expression of SRIF and GHRH in the hypothalamus of sheep. Ovariectomised ewes were randomly divided into two groups and either fed an ad lib diet $(n=6)$ or a restricted diet of $500 \mathrm{~g}$ lucerne chaff per day (food-restricted; $n=5$ )
\end{abstract}

for 7 months. In situ hybridisation was used to study hypothalamic gene expression for GHRH, SRIF and galanin (GAL). The food-restricted animals had elevated plasma concentrations of $\mathrm{GH}$; this was associated with an increase in GHRH mRNA levels in the arcuate nucleus (ARC) and reduced SRIF in the rostral periventricular nucleus and ventromedial hypothalamic nucleus. The level of gene expression of GAL in the ARC and SRIF in the caudal periventricular nucleus was similar in ad lib and food-restricted animals. In conclusion, the effect of chronic food-restriction on the secretion of $\mathrm{GH}$ reflects increased GHRH and reduced SRIF synthesis in the hypothalamus. Journal of Endocrinology (2001) 170, R1-R6

\section{Introduction}

The secretion of GH is highly susceptible to changes in nutritional status in all species studied to date. Undernutrition increases the secretion of GH in man (Stoving et al. 1999) and sheep (Foster et al. 1989, Thomas et al. 1990). Conversely, plasma GH levels are reduced in food-restricted or fasted rodents (Tannenbaum et al. 1979). In the obese state, both basal and stimulated secretion of GH is reduced in man (Williams et al. 1984) and rodents (Renier et al. 1990).

The episodic release of GH from the somatotroph is predominantly controlled by somatostatin (SRIF) and growth hormone-releasing hormone $(\mathrm{GHRH})$, which are secreted from the hypothalamus to exert inhibitory and stimulatory effects respectively. To what extent both SRIF and GHRH mediate the altered secretion of GH due to nutritional status remains unknown; no studies have been performed in species where GH is increased by undernutrition. Some progress, however, has been made in the fasted rodent in which GHRH mRNA and peptide levels are down-regulated (Bruno et al. 1990, Brogan et al. 1997) by acute under-nutrition. Despite this, there is only a small effect (Brogan et al. 1997), if any (Bruno et al. 1990), on the level of SRIF mRNA and peptide. On the other hand, food-restricted sheep have reduced SRIF concentrations in the hypophyseal portal circulation whereas GHRH levels in this model appear to be maintained (Thomas et al. 1991).

It is important to note that previous mRNA studies have been performed on whole rodent hypothalamic tissue. SRIF-containing neurons are abundant throughout the hypothalamus in rats (Bennett-Clarke et al. 1980), sheep (Willoughby et al. 1995) and man (Langevin \& Emson 1982) and previous studies have not accounted for the specific regional variations in expression that one might expect. Indeed, neuronal tracing studies in rodents have shown that the SRIF neurons from the rostral periventricular nucleus $(\mathrm{PeVN})$ are solely responsible for the projections to the median eminence (Kawano \& Daikoku 1988).

The current study aimed to determine the effects of chronic food-restriction on the expression of GHRH in the ARC and SRIF in the rostral and caudal periventricular nucleus (rPeVN, cPeVN) and the ventromedial hypothalamic nucleus $(\mathrm{VMH})$. The effect of nutrition on the mRNA levels for galanin (GAL) was also measured, since this peptide stimulates GH secretion (Ottlecz et al. 1986, Bauer et al. 1986, Spencer et al. 1994). 


\section{Materials and Methods}

Ethics

This work was approved in advance by the Animal Experimentation Ethics Committees of Monash University and Victorian Institute of Animal Science.

\section{Animals}

Ovariectomised Corriedale ewes were randomly divided into two groups and fed either an ad lib diet of lucerne chaff and $1 \mathrm{~kg}$ lupin grain per week or a restricted diet of $500 \mathrm{~g}$ of chaff per day as previously described (Henry et al. 2001). At the time of experimentation the food-restricted animals $(n=5)$ had significantly $(P<0.001)$ lower body weights compared with the ad lib fed animals $(n=6)$ $(30 \cdot 8 \pm 1 \cdot 3 \mathrm{~kg}$ vs $53 \cdot 4 \pm 2 \cdot 2 \mathrm{~kg})$ and elevated plasma levels of $\mathrm{GH}(P<0.001)(11.6 \pm 0.6 \mathrm{ng} / \mathrm{ml}$ vs $5.5 \pm 0.9 \mathrm{ng} / \mathrm{ml})$, as previously reported (Henry et al. 2001). Serial blood samples were taken every $10 \mathrm{~min}$ for $8 \mathrm{~h}$ for the measurement of GH. Although the animals were previously treated with leptin (Henry et al. 2001), GH determinants were performed prior to this and the animals were killed 1 month later (to ensure that there was no confounding effect of the leptin infusion). Throughout this period the animals were maintained on either the restricted or ad lib diet.

\section{Tissue collection preparation and in situ hybridisation}

The animals were killed by humane means and the brains perfusion fixed with a series of paraformaldehyde solutions (Henry et al. 2000). Frozen sections were cut at $20 \mu \mathrm{m}$ using a cryostat and then stored at $-20{ }^{\circ} \mathrm{C}$ in $2 \%$ PFA/ cryoprotectant solution. At least two sections were anatomically matched, pair-mounted onto Super Frost Plus slides (Menzel-Glaser, Braunschweig, Germany) and dried overnight at room temperature. In situ hybridisation was performed using ${ }^{35} \mathrm{~S}$-dUTP-labeled (Amersham Pharmacia Biotech, Sydney, Australia) riboprobes following the method of Simmons et al. (1989). The cDNA and plasmid inserts used were a 220 bp human galanin insert in BSKII (Evans et al. 1992), a 160 bp rat GHRH insert in pGemT-easy and a 420 bp rat SRIF insert in pGem-4 (Fuller \& Verity 1989). The rat GHRH cRNA probe was PCR cloned from hypothalamic tissue using the primers 5' hGHRH-105 (AGA TGC CAT CTT CAC CAR CAG CT) and 3' hGHRH-250 (ATT TGC TTT TGY TCT GCC CAC AY) (Gibco BRL, New York, USA). Amplification, purification and linearisation of plasmid DNA were performed using standard techniques (Sambrook et al. 1989). All cRNA probes were synthesised using a Gemini system II kit (Promega Corp., Annandale, New South Wales, Australia). Hybridisation signal was detected using a Molecular Dynamics Storm PhosphorImager (Amersham Pharmacia Biotech, UK Ltd,
Buckinghamshire, England). Sections hybridised for SRIF were exposed for 1 day, whereas those for GHRH and GAL were exposed for 3 days. Slides were then dipped in photographic emulsion (Ilford Australia, Mount Waverly, Victoria, Australia) and exposed at $4{ }^{\circ} \mathrm{C}$ for 2,14 and 21 days for SRIF, GAL and GHRH respectively. The slides were then developed using Ilford Phenisol X-ray developer, stop-bath and Hypam fixer, then counterstained with $1 \%$ cresyl violet, dehydrated and coverslipped using DPX.

\section{Data and statistical analysis}

For each sheep one section representing each region was selected and 20 cells were randomly chosen (unless the total number of cells was less than 20) for silver grain analysis. A cell was deemed labeled if the number of silver grains exceeded the adjacent background reading by 7 times. This was performed at 400x magnification using a microcomputer imaging device (MCID) M1 system from the Imaging Research, Inc. (Brock University, St Catharines, Ontario, Canada). The total number of labeled cells was counted at 20x magnification. Direct comparisons of silver grains/cell were made between ad lib and food-restricted animals using a single factor ANOVA after checking for homogeneity of variance; SRIF silver grains/ cell for the VMH were subjected to $\log$ transformation. Data for the number of labeled cells were analysed by the Mann Whitney $U$ test for unpaired samples. Correlation analysis was performed to determine the association between plasma levels of GH and gene expression.
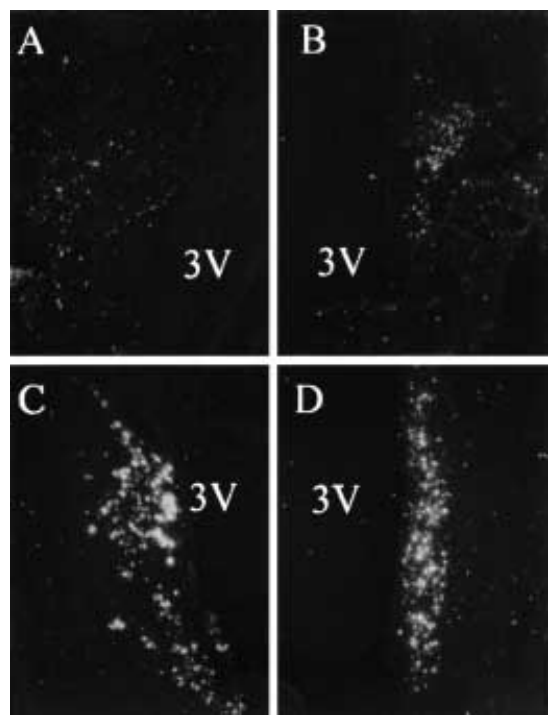

FIGURE 1 Representative darkfield micrographs $(2 \mathrm{x}$ magnification) of GHRH-labelled cells in the ARC (A,B) and SRIF-labelled cells in the rPeVN (C,D). Panels A and C correspond to ad lib and panels B and D the food-restricted groups. $3 \mathrm{~V}$ : third ventricle. 

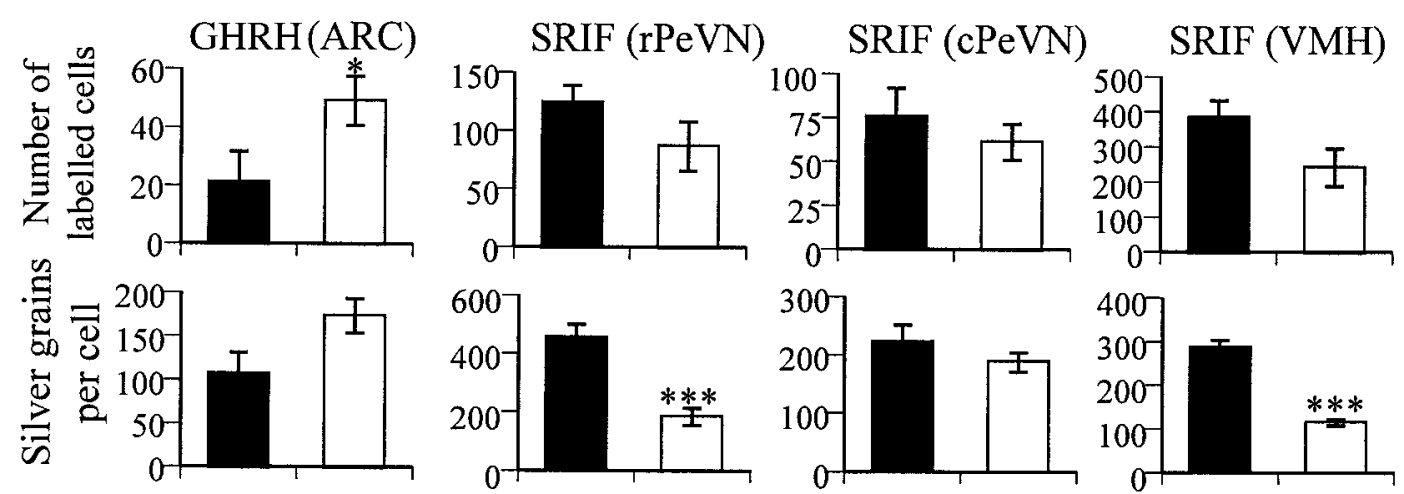

FIgURE 2 The effect of nutritional status on the gene expression of GHRH and SRIF in ad lib $(n=6$; closed bars) and food-restricted ( $n=5$; open bars) sheep. All data are presented as mean $\left( \pm\right.$ S.E.M.). ${ }^{*} P<0 \cdot 05$,

${ }^{* *} P<0 \cdot 0001$

\section{Results}

Examples of hybridisation signals for GHRH and SRIF are shown in Fig. 1. The number of GHRH-labeled cells in the ARC was higher $(P<0 \cdot 01)$ in the food-restricted animals but the number of GHRH silver grains/cell was similar between the two groups (Fig. 2). The number of SRIF-labeled cells in all three regions, the rPeVN and cPeVN and the VMH, was similar in the food-restricted and ad lib fed animals (Fig. 2). The number of silver grains/cell for SRIF in the rPeVN and the VMH was lower $(P<0.01)$ in the food-restricted group, with no effect of nutritional status on the number of silver grains/ cell for SRIF in the cPeVN (Fig 2.). Expression of GAL mRNA was similar in the two groups (data not shown).

Mean plasma GH concentrations were negatively correlated $(P<0 \cdot 01)$ to the number of silver grains per SRIF cell in the $\mathrm{rPeVN}$ and the $\mathrm{VMH}(r=-0 \cdot 77, P<0 \cdot 001$; data not shown) but not the $\mathrm{cPeVN}$ (Fig. 3). There was no significant correlation between $\mathrm{GH}$ levels and the number of SRIF-labeled cells for any given region. Neither was the number of GHRH-labeled cells nor the number of silver grains per cell for GHRH correlated with mean plasma GH levels (Fig. 3).

\section{Discussion}

We show an effect of nutrition on the expression of SRIF mRNA, which is specific to particular hypothalamic nuclei; there was a reduction in the $\mathrm{rPeVN}$ and the $\mathrm{VMH}$, but not the cPeVN in food-restricted sheep. Furthermore, the changes in the number of silver grains/cell for SRIF in the rPeVN and the VMH were negatively correlated with alterations in plasma GH levels. The expression of GHRH mRNA was increased in the ARC in food-restricted animals, but these changes were not correlated to the secretion of GH. Whilst gene expression and the pulsatile release of these neurohormones may not be correlated in the strictest sense, our results are consistent with an upregulation of the $\mathrm{GH}$ axis at the hypothalamic level in the food-restricted animals. Previous studies in rodents have shown that SRIF cell bodies in the rPeVN project to the median eminence (Kawano \& Daikoku 1988) and are most likely to be involved in the regulation of $\mathrm{GH}$ secretion; the current results are consistent with this notion. The expression of SRIF was reduced in the $\mathrm{rPeVN}$ of the food-restricted animals concordant with increased $\mathrm{GH}$ secretion in this group. In contrast, SRIF projections from the $\mathrm{VMH}$ to the median eminence have not been identified (Kawano \& Daikoku 1988) and whether decreased SRIF mRNA levels in this area relate to increased
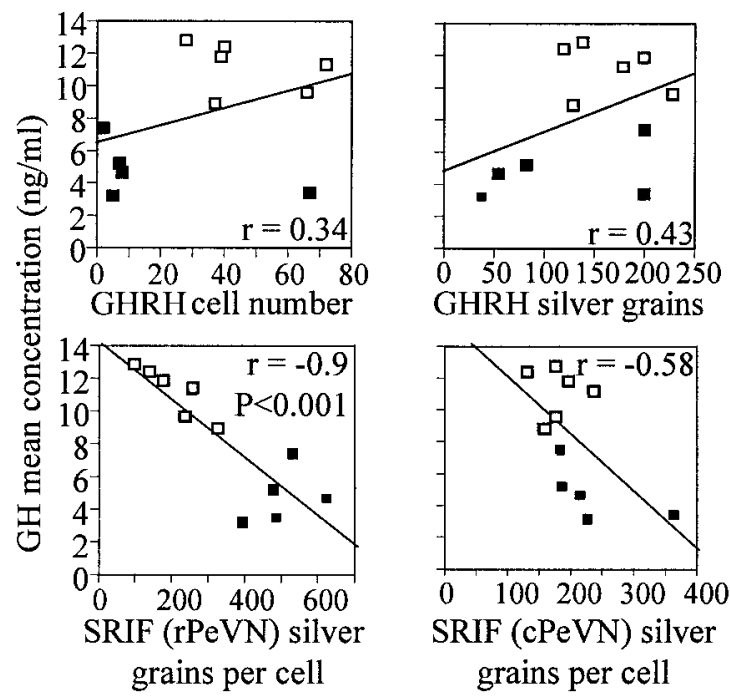

FIgure 3 Correlation studies in ad lib (Closed squares) and food-restricted (open squares) animals. The SRIF silver grains per cell in the $\mathrm{rPeVN}$ were negatively orrelated $(P<0 \cdot 01)$ with the mean plasma concentrations of GH. 
$\mathrm{GH}$ levels in food-restricted animals remains unknown. SRIF is expressed throughout the central nervous system, is implicated in various bodily functions, and is thought to act as a central neurotransmitter (Olpe et al. 1980).

Central administration of SRIF has been shown to regulate food intake in rodents but results remain controversial, with SRIF reported to decrease (Lin et al. 1987, Ho et al. 1989), to increase (Danguir 1988), or to induce a biphasic effect (Aponte et al. 1984) on feeding behaviour. The effects of SRIF on feeding appear to be dosedependent, with low doses stimulating and high doses inhibiting food intake (Feifel \& Vaccarino 1990). The $\mathrm{VMH}$ is integral to the regulation of feeding (Luiten et al. 1987) and decreased expression of SRIF in this region may relate to altered appetite drive in food-restricted animals. It is possible to invoke a mechanism, whereby decreased SRIF mRNA levels in the VMH, and low SRIF levels, may be translated into increased hunger-drive in the food-restricted group. These animals are indeed hungry as when fed an ad lib diet of lucerne hay their voluntary food intake doubles (Henry et al. 2001).

A role for SRIF in the VMH in mediating the secretion of $\mathrm{GH}$ can not be dismissed however. In the current study the expression of SRIF in the VMH was negatively correlated to the mean plasma $\mathrm{GH}$ concentrations. Although there are no direct projections from the VMH to the median eminence (Kawano \& Daikoku 1988), SRIF may exert an effect on the secretion of GH by modulating GHRH release. Radiolabeling studies have identified SRIF binding sites in the ventrolateral ARC and approximately $35 \%$ of the GHRH cells in the ARC contain SRIF-receptors (McCarthy et al. 1992). It is possible that decreased SRIF expression in the VMH could lead to a lowered inhibitory input to GHRH cells of the ARC and a consequent increase in $\mathrm{GH}$ secretion. In addition to the alterations in SRIF, the expression of GHRH mRNA was increased in the ARC of the food-restricted animals, consistent with the higher plasma GH levels in this group. Despite this, however, expression of GHRH mRNA was not correlated to the mean plasma concentrations of $\mathrm{GH}$ suggesting that SRIF may be the primary controller in mediating the increased secretion of $\mathrm{GH}$ in food-restricted animals. In accordance with this, previous studies from our laboratory have shown that the hypophyseal portal concentrations of SRIF are lower in under-fed ewes but the concentrations of GHRH are unchanged (Thomas et al. 1991). It remains possible that small changes in the secretion of GHRH may occur, but levels in portal blood are very low and close to the limit of detection (Thomas et al. 1991).

Cells containing GHRH have been shown to project to multiple sites within the central nervous system (Merchenthaler et al. 1984) apart from the median eminence, suggesting that GHRH is involved in mediating functions other than the secretion of GH. Like SRIF, $\mathrm{GHRH}$ has been implicated in the control of feeding behaviour, having been shown to enhance food intake in rats (Vaccarino et al. 1985) and sheep (Ruckebusch \& Malbert 1986). In addition to the regulation of $\mathrm{GH}$ secretion, increased GHRH mRNA levels may precede an up-regulation in hunger-drive in food-restricted sheep.

We investigated expression of GAL due to the welldocumented stimulatory effects of this peptide on the secretion of GH (Ottlecz et al. 1986, Spencer et al. 1994). The expression of GAL in the ARC was similar in the ad lib and food-restricted animals. Evidence suggests that the effects of GAL on the secretion of $\mathrm{GH}$ involve SRIF-ergic inhibition (Loche et al. 1990, Tanoh et al. 1993) and GAL cells in the ARC project to the SRIF neurons in the PeVN (Liposits et al. 1993). It is likely, therefore, that any effect on the GAL system may manifest as changes in the levels of SRIF in the PeVN and our results for the $\mathrm{rPeVN}$ are consistent with this.

In conclusion, the effects of chronic under-nutrition to elevate the secretion of GH may result from increased GHRH and decreased SRIF synthesis. Furthermore, the effects of nutrition on the expression of SRIF are specific to particular regions of hypothalamus and it is likely that SRIF in the rPeVN is most relevant to the control of the secretion of GH. In addition to effects on the secretion of GH, both GHRH and SRIF could possibly be involved in the regulation of feeding behaviour; decreased gene expression for SRIF in the VMH may be linked to such a function.

\section{Acknowledgments}

We wish to acknowledge Mr Bruce Doughton and Mrs Karen Briscoe for animal care, Dr. Peter Fuller for supplying the SRIF probe and Dr. John Shine for the GAL probe. This work was supported by NHMRC of Australia and we thank PHIMR for stipend support for BAH.

\section{References}

Aponte G, Leung P, Gross D \& Yamada T 1984 Effects of somatostatin on food intake in rats. Life Sciences 35 741-746.

Bauer FE, Ginsberg L, Venetikou M, MacKay DJ, Burrin JM \& Bloom SR 1986 Growth hormone release in man induced by galanin, a new hypothalamic peptide. Lancet 2 192-195.

Bennett-Clarke C, Romagnano MA \& Joseph SA 1980 Distribution of somatostatin in the rat brain: telencephalon and diencephalon. Brain Research 188 473-486.

Brogan RS, Fife SK, Conley LK, Giustina A \& Wehrenberg WB 1997 Effects of food deprivation on the GH axis: immunocytochemical and molecular analysis. Neuroendocrinology $6 \mathbf{5}$ $129-135$.

Bruno JF, Olchovsky D, White JD, Leidy JW, Song J \& Berelowitz M 1990 Influence of food deprivation in the rat on hypothalamic expression of growth hormone-releasing factor and somatostatin. Endocrinology 127 2111-2116.

Danguir J 1988 Food intake in rats is increased by intracerebroventricular infusion of the somatostatin analogue SMS 201-995 and is decreased by somatostatin antiserum. Peptides 9 211-213. 
Evans HF, Huntley GW, Morrison JH, Shine J \& Paxinos G 1992 Localization of preprogalanin mRNA in the monkey hippocampal formation. NeuroscienceLetters 146 171-175.

Feifel D \& Vaccarino FJ 1990 Central somatostatin: a re-examination of its effects on feeding. Brain Research 535 189-194.

Foster DL, Ebling FJP, Micka AF, Vannerson LA, Bucholtz DC, Wood RI, Suttie JM \& Fenner DE 1989 Metabolic interfaces between growth and reproduction. I. Nutritional modulation of gonadotropin, prolactin and growth hormone secretion in the growth-limited female lamb. Endocrinology 125 342-350.

Fuller PJ \& Verity K 1989 Somatostatin gene expression in the thymus gland. Journal of Immunology 143 1015-1017.

Henry BA, Goding JW, Tilbrook AJ, Dunshea FR \& Clarke IJ 2001 Intracerebroventricular infusion of leptin elevates the secretion of luteinising hormone without affecting food intake in long-term food-restricted sheep, but increases growth hormone irrespective of bodyweight. Journal of Endocrinology 168 67-77.

Henry BA, Tilbrook AJ, Dunshea FR, Rao A, Blache D, Martin GB \& Clarke IJ 2000 Long-term alterations in adiposity affect the expression of melanin- concentrating hormone and enkephalin but not proopiomelanocortin in the hypothalamus of ovariectomized ewes. Endocrinology 141 1506-1514.

Ho LT, Chern YF \& Lin MT 1989 The hypothalamic somatostatinergic pathways mediate feeding behavior in the rat. Experientia 45 161-162.

Kawano H \& Daikoku S 1988 Somatostatin-containing neuron systems in the rat hypothalamus: retrograde tracing and immunohistochemical studies. Journal of Comparitive Neurology 271 293-299.

Langevin H \& Emson PC 1982 Distribution of substance P, somatostatin and neurotensin in the human hypothalamus. Brain Research 246 65-69.

Lin MT, Chen JJ \& Ho LT 1987 Hypothalamic involvement in the hyperglycemia and satiety actions of somatostatin in rats. Neuroendocrinology 45 62-67.

Liposits Z, Merchenthaler I, Reid JJ \& Negro-Vilar A 1993 Galanin-immunoreactive axons innervate somatostatin-synthesizing neurons in the anterior periventricular nucleus of the rat. Endocrinology 132 917-923.

Loche S, Vista N, Ghigo E, Vannelli S, Arvat E, Benso L, Corda R, Cella SG, Muller EE \& Pintor C 1990 Evidence for involvement of endogenous somatostatin in the galanin-induced growth hormone secretion in children. PediatricResearch 27 405-407.

Luiten PG, Ter Horst GJ \& Steffens AB 1987 The hypothalamus, intrinsic connections and outflow pathways to the endocrine system in relation to the control of feeding and metabolism. Progress in Neurobiology 28 1-54.

McCarthy GF, Beaudet A \& Tannenbaum GS 1992 Colocalization of somatostatin receptors and growth hormone-releasing factor immunoreactivity in neurons of the rat arcuate nucleus. Neuroendocrinology 56 18-24.

Merchenthaler I, Thomas CR \& Arimura A 1984 Immunocytochemical localization of growth hormone releasing factor (GHRF)containing structures in the rat brain using anti-rat GHRF serum. Peptides 5 1071-1075.

Olpe HR, Balcar VJ, Bittiger H, Rink H \& Sieber P 1980 Central actions of somatostatin. European Journal of Pharmacology 63 127-133.
Ottlecz A, Samson WK \& McCann SM 1986 Galanin: evidence for a hypothalamic site of action to release growth hormone. Peptides 7 51-53.

Renier G, Gaudreau P, Hajjad H, Deslauriers N, Houde-Nadeau M \& Brazeau P 1990 Decreased pituitary growth hormone response to growth hormone-releasing factor in cafeteria-fed rats: dietary and obesity effects. Neuroendocrinology 52 284-290.

Ruckebusch Y \& Malbert CH 1986 Stimulation and inhibition of food intake in sheep by centrally- administered hypothalamic releasing factors. Life Sciences 38 929-934.

Sambrook J, Fritsch EF \& Maniatis T 1989 Molecular Cloning: A Laboratory Manual. New York: Cold Spring Harbour Laboratory Press.

Simmons DM, Arriza JL \& Swanson LW 1989 A complete protocol for in situ hybridization of messenger RNAa in brain and other tissues with radio-labeled single-stranded RNA probes. Journal of Histotechnology 12 169-181.

Spencer GS, Berry CJ \& Bass JJ 1994 Neuroendocrine regulation of growth hormone secretion in sheep. VI. Intracerebroventricular administration of galanin. Neuroreport 5 522-524.

Stoving RK, Hangaard J, Hansen-Nord M \& Hagen C 1999 A review of endocrine changes in anorexia nervosa. Journal of PsychiatricResearch 33 139-152.

Tannenbaum GS, Rorstad O \& Brazeau P 1979 Effects of prolonged food deprivation on the ultradian growth hormone rhythm and immunoreactive somatostatin tissue levels in the rat. Endocrinology 104 1733-1738.

Tanoh T, Shimatsu A, Ishikawa Y, Ihara C, Yanaihara N \& Imura H 1993 Galanin-induced growth hormone secretion in conscious rats: evidence for a possible involvement of somatostatin. Journal of Neuroendocrinology 5 183-187.

Thomas GB, Cummins JT, Francis H, Sudbury AW, McCloud PI \& Clarke IJ 1991 Effect of restricted feeding on the relationship between hypophysial portal concentrations of growth hormone (GH)-releasing factor and somatostatin, and jugular concentrations of GH in ovariectomized ewes. Endocrinology 128 1151-1158.

Thomas GB, Mercer JE, Karalis T, Rao A, Cummins JT \& Clarke IJ 1990 Effect of restricted feeding on the concentrations of growth hormone $(\mathrm{GH})$, gonadotropins, and prolactin (PRL) in plasma, and on the amounts of messenger ribonucleic acid for $\mathrm{GH}$, gonadotropin subunits, and PRL in the pituitary glands of adult ovariectomized ewes. Endocrinology 126 1361-1367.

Vaccarino FJ, Bloom FE, Rivier J, Vale W \& Koob GF 1985 Stimulation of food intake in rats by centrally administered hypothalamic growth hormone-releasing factor. Nature $\mathbf{3 1 4}$ 167-168.

Williams T, Berelowitz M, Joffe SN, Thorner MO, Rivier J, Vale W \& Frohman LA 1984 Impaired growth hormone responses to growth hormone-releasing factor in obesity. A pituitary defect reversed with weight reduction. New England Journal of Medicine 311 1403-1407.

Willoughby JO, Oliver JR, Fletcher TP \& Clarke IJ 1995 Distribution of somatostatin immunoreactivity in sheep hypothalamus: a comparison with that of the rat. Archives of Histology \& Cytology 58 31-36. 